\title{
Fourth BCS-IRSG Symposium on Future Directions in Information Access (FDIA 2011)
}

\author{
31 August 2011 \\ Koblenz, Germany
}

\author{
Editors \\ Liadh Kelly \\ Leif Azzopari
}




\section{Abstract}

In 2007, the first BCS-IRSG Symposium on Future Directions in Information Access (FDIA) was established to provide a forum for early career researchers to present, share and discuss research, which is at a more formative or tentative stage. The symposium was run in conjunction with the 6th European Summer School in Information Retrieval (ESSIR) which was held in Glasgow. The second symposium was held in London, UK in September, 2008 collocated with Search Solutions, while the third symposium was again collocated with ESSIR in Padua, Italy. Now in its fourth year, the 2011 Future Directions in Information Access Symposium was held as part of the 8th European Summer School in Information Retrieval.

\section{Symposium aims}

The objectives of the Symposium on the Future Directions in Information Access are:

$>$ to provide an accessible forum for early researchers (particularly PhD students, and researchers new to the field) to share and discuss their research;

$>$ to create and foster formative and tentative research ideas;

$>$ to encourage discussion and debate about new future directions.

\section{Sponsors:}

BCS-IRSG (Information Retrieval Specialist Group)

Centre for Next Generation Localisation (CNGL)

European Summer School in Information Retrieval (ESSIR) 


\section{Full Synopsis}

These proceedings contain papers and posters presented at the 4th Symposium on Future Directions in Information Access, which was held in Koblenz, Germany on 31 August during the 2011 European Summer School in Information Retrieval (ESSIR).

This year's programme featured an inspiring keynote by David Elsweiler entitled 'Working at (and pushing) the boundaries of IR', while Liadh Kelly presented 'Nine things I wish I knew about doing a PhD', before four of the students presented their work. To create an interactive and dynamic session, this year we introduced a speed dating session where the participants paired up for two minutes each and brainstormed on future directions for the field. After each speed date, the couples came up with a new topic that combined their research areas. An overview of the emerging topics can be seen in the tag cloud.

In the final session of the day all the participants of the summer school presented posters and further discussed their research in a friendly and fun atmosphere.

The organisers would like to thank: the members of the programme committee for all their hard work and effort in providing excellent feedback and reviews; David Elsweiler for delivering a stimulating and thought-provoking keynote on how research in other fields influences IR research, how exploring the boundaries of IR research opens up new problems, and how we should not be afraid to push the boundaries and tackle these new challenges. We would also like to thank ESSIR 2011 and the University of Koblenz for hosting the event, and in particular Ruth Ehrenestein for her assistance in local organisation. We would like to extend our thanks to the Centre for Next Generation Localisation (CNGL), Ireland for their financial assistance and the BCS-IRSG for sponsoring the event. 


\section{Editors}

Liadh Kelly, Dublin City University

Leif Azzopari, University of Glasgow 


\section{Papers:}

\section{Full Papers}

Chandan Kumar Relevance and Ranking in Geographic Information Retrieval http://dx.doi.org/10.14236/ewic/FDIA2011.1

Saúl Vargas New Approaches to Diversity and Novelty in Recommender Systems http://dx.doi.org/10.14236/ewic/FDIA2011.2

\section{Short Papers}

Markus Borg IR-based Traceability Recovery as a Plugin - An Industrial Case Study http://dx.doi.org/10.14236/ewic/FDIA2011.3

Juliano Augusto Carreira Database Enrichment Environment to Identify Duplicate Tuples http://dx.doi.org/10.14236/ewic/FDIA2011.4

Somayeh Khatiban Retrieving and Connecting Reputations to Find Reliable Results http://dx.doi.org/10.14236/ewic/FDIA2011.5

\section{Abstracts}

Debasis Ganguly Utilizing Sub-topical Structure of Documents for Information Retrieval http://dx.doi.org/10.14236/ewic/FDIA2011.6

Wei Li Exploring Recommenders for Improved Information Retrieval http://dx.doi.org/10.14236/ewic/FDIA2011.7 